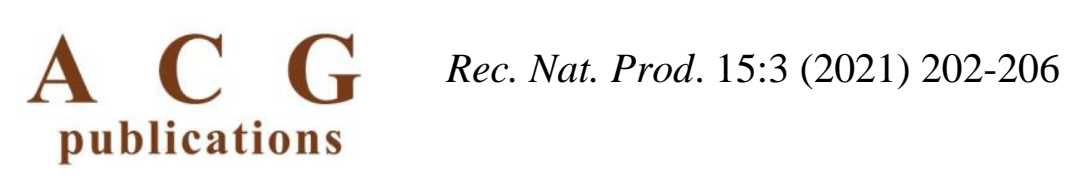

\title{
Aromatic Rosane-type Diterpenoid with Lipase Inhibitory Effect from Euphorbia ebracteolata and Chemotaxonomic Significance of Diterpenoids
}

\author{
Jian Zhou $\oplus^{1}$, Jinhua Wen $\odot^{1}$, Jianhua Huang $\odot^{2}$, Pengfei Chen $\odot^{1}$, \\ Xiaochi Ma $\oplus^{3}$, Rongjing Sun $\oplus^{4 *}$ and Chao Wang $\oplus^{3 *}$ \\ ${ }^{I}$ Department of Pharmacy, the First Affiliated Hospital of Nanchang University, Nanchang, \\ Jiangxi330006, P. R. China \\ ${ }^{2}$ Department of Pharmacy, Health-Center of Jingba Town, Ganzhou, Jiangxi341408, P. R. China \\ ${ }^{3}$ College of Pharmacy, Dalian Medical University, Dalian, Liaoning 116044, P. R. China \\ ${ }^{4}$ College of Pharmacy, University of Houston, Houston, Texas 77204, United States
}

(Received August 18, 2020; Revised October 10, 2020; Accepted October 14, 2020

\begin{abstract}
The phytochemical investigation has been performed for Euphorbia ebracteolata, the roots of which are usually used natural medicine in traditional Chinese medicine for the treatments of tuberculosis and bacterial infection. A diterpenoid has been obtained using silica gel and ODS column chromatography. Furthermore, on the basis of widely spectroscopic data analyses, including 1D-, 2D-NMR, HR-ESIMS and ECD, the isolated compound was determined to be a rosane type diterpenoid, which possessed a rare aromatic ring. The isolated diterpenoid as a new compound was named ebraphenol E (1). The bioactivity of isolated diterpenoid (1) has been evaluated and moderate inhibitory effect on lipase $\left(\mathrm{IC}_{50}=12.5 \mu \mathrm{M}\right)$ was observed. In combination with our previous phytochemical investigations about E. ebracteolata, the chemotaxonomic significance of diterpenoids was summarized for E. ebracteolata.
\end{abstract}

Keywords: Euphorbia ebracteolata; rosane diterpenoid; ebraphenol E; lipase; chemotaxonomy. (C) 2020 ACG Publications. All rights reserved.

\section{Plant Source}

The roots of Euphorbia ebracteolata (No. 79452, World Checklist of Selected Plant Families) were purchased from Bozhou City of Anhui province in China and identified by Prof. Qing-shan Yang of Anhui University of Chinese Medicine. A voucher specimen (P-231) was deposited in the College of Pharmacy, Dalian Medical University.

\section{Previous Studies}

Euphorbia ebracteolata Hayata belonging to the Euphorbiaceae family, widely distributed in China. The dried root of E. ebracteolata is one of the two origins of the traditional Chinese medicine (TCM) "Lang Du", which is also used to treat pulmonary tuberculosis, chronic tracheitis, and psoriasis in TCM [1]. Previous phytochemical investigations of this plant led to the isolation of diterpenoids [2],

\footnotetext{
*Corresponding author: E-mail addresses: rsun5@uh.edu (Rongjing Sun) and wach_edu@ sina.com (Chao Wang)
} 
triterpenoids [3], sesquiterpenoids [4], flavonols [5], acetophenones [6], and steroids [7]. Especially, diterpenoids as the major constituents of E. ebracteolata displayed a wide spectrum of bioactivities, including anti-tumor [8-9], anti-inflammatory [10], anti-HIV [11], and anti-tuberculosis [12]. In our previous work, 40 new and 45 known compounds were isolated from the ethanoic extracts of the roots of E. ebracteolata [12-20].

\section{Present Study}

The dried roots of E. ebracteolata $(15 \mathrm{~kg})$ were powdered and extracted with $80 \% \mathrm{EtOH}(150$ $\mathrm{L} ; 3 \times 1.5 \mathrm{~h}$ ) under reflux. After evaporation of ethanol in vacuum, the suspension solution for total extracts in water was diluted with $\mathrm{H}_{2} \mathrm{O}$. The aqueous residue was sequentially partitioned with petroleum ether, EtOAc, and $n-\mathrm{BuOH}$. Then, chromatographic experiment has been performed for EtOAc extract $(504 \mathrm{~g})$ using silica gel chromatography column, which was eluted with petroleum ether/acetone (50:1-2:1, v/v) mixed solvents, along with the preparation of 55 fractions. The chromatographic fraction $6(45 \mathrm{~g})$ was further separated into sub-fractions A1-A18 by MPLC (ODS) using $\mathrm{MeOH}: \mathrm{H}_{2} \mathrm{O}$ (50:50-100:0, v/v) mixed solvents as the eluent. Compound 1 ( $3.5 \mathrm{mg}, t_{\mathrm{R}} 35.6 \mathrm{~min}$ ) was isolated from sub-fraction A10 $(100 \mathrm{mg})$ by preparative HPLC ( $\lambda 250$ and $280 \mathrm{~nm})$ with a $\mathrm{MeOH}: \mathrm{H}_{2} \mathrm{O}$ mixture (60:40, v/v) as the eluent (flow rate $8 \mathrm{~mL} / \mathrm{min}$ ).

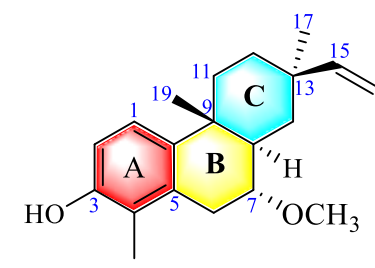

1

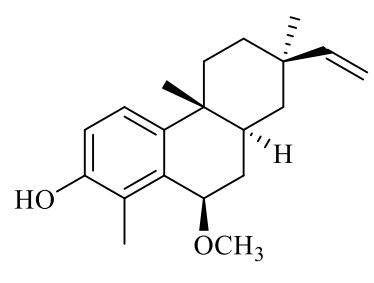

2

Figure 1. Structure of rosane diterpenoid ebraphenol E (1) and ebraphenol B (2)

Ebraphenol E (1): White amorphous powder; UV(CH$\left.{ }_{3} \mathrm{OH}\right) \lambda_{\max } 285.5 \mathrm{~nm}$; (+)-HR-ESIMS $\mathrm{m} / \mathrm{z}$ $323.1980[\mathrm{M}+\mathrm{Na}]^{+}$(calcd. for $\left.\mathrm{C}_{20} \mathrm{H}_{28} \mathrm{O}_{2} \mathrm{Na}, 323.1987\right)$; ${ }^{1} \mathrm{H}$ NMR $\left(\mathrm{CDCl}_{3}, 600 \mathrm{MHz}\right)$ data and ${ }^{13} \mathrm{C}$ NMR $\left(\mathrm{CDCl}_{3}, 150 \mathrm{MHz}\right)$ data see Table 1 .

Compound 1 was obtained as a white amorphous powder. Its molecular formula was determined to be $\mathrm{C}_{20} \mathrm{H}_{28} \mathrm{O}_{2}$ by HRESIMS at positive ion peak $m / z 323.1980[\mathrm{M}+\mathrm{Na}]^{+}$. In the ${ }^{1} \mathrm{H} N M R$ spectrum of $\mathbf{1}$, proton signals suggested the existences of an $\mathrm{AB}$ spin system $\delta_{\mathrm{H}} 7.03(\mathrm{~d}, J=8.4 \mathrm{~Hz}, \mathrm{H}-$ 1) and $6.72(\mathrm{~d}, J=8.4 \mathrm{~Hz}, \mathrm{H}-2)$; a terminal double bond $\delta_{\mathrm{H}} 5.86(\mathrm{dd}, J=17.4,10.8 \mathrm{~Hz}, \mathrm{H}-15), 4.97$ (dd, $J=17.4,1.2 \mathrm{~Hz}, \mathrm{H}-16 \mathrm{a})$, and 4.90 (dd, $J=10.8,1.2 \mathrm{~Hz}, \mathrm{H}-16 \mathrm{~b})$; three angular methyl groups $\delta_{\mathrm{H}}$ 0.99 (s, 3H, H-17), 2.21 (s, 3H, H-18), and 1.12 (s, 3H, H-19); one methoxy group $\delta_{\mathrm{H}} 3.39$ (s, 3H) (Table 1). On the other hand, twenty carbons were observed in the ${ }^{13} \mathrm{C}$ NMR spectrum of compound $\mathbf{1}$, which confirmed the existences of terminal double bond $\left(\delta_{\mathrm{C}} 150.9,109.0\right)$, methoxy moiety $\left(\delta_{\mathrm{C}} 54.9\right)$, as well as the indicated aromatic group $\left(\delta_{\mathrm{C}} 122.2,114.6,152.0,124.3,135.2,142.5\right)$ (Table 1). On the basis of widely spectroscopic data analyses, compound $\mathbf{1}$ was deduced to be a diterpenoid possessing an aromatic ring, which was similar to reported rosane type diterpenoid ebraphenol B (2) isolated from E. ebracteolata [20]. In the HMBC spectrum, the long range correlations from $\mathrm{H}-1$ to $\mathrm{C}-3, \mathrm{C}-5$, and C10, from $\mathrm{H}-2$ to $\mathrm{C}-4, \mathrm{C}-10$, and from $\mathrm{CH}_{3}-18$ to $\mathrm{C}-3, \mathrm{C}-5$ established the ortho-tetrasubstituted benzene ring $\mathrm{A}$ for isolated diterpenoid (1) (Figure 1). The rosane type diterpenoid skeleton was furtherly confirmed by the establishment of $\mathrm{CH}_{3}-17$ (H-17/C-12, C-14, C-15) and $\Delta^{15,16}$ double bond (H-16/C-13). Based on abovementioned spectroscopic data, compound 1 was deduced to be similar to $\mathbf{2}$ except for the methoxy group at C-7 in $\mathbf{1}$ instead of at C-6 in compound $\mathbf{2}$. This assignment was confirmed by the HMBC correlations from the protons of methoxy group $\left[\delta_{\mathrm{H}} 3.39(3 \mathrm{H}, \mathrm{s})\right]$ to $\mathrm{C}-7\left(\delta_{\mathrm{C}}\right.$ 74.8) (Figure 2). 
(a)

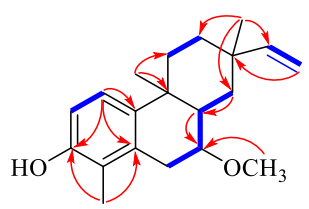

(b)

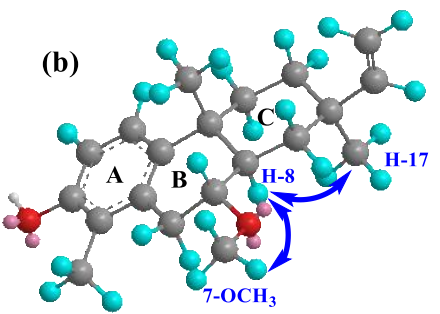

Figure 2. (a) Key HMBC (from $\mathrm{H}$ to $\mathrm{C}$, red lines) and ${ }^{1} \mathrm{H}-{ }^{1} \mathrm{H}$ COSY correlations (blue lines) of ebraphenol E. (b) key NOESY correlations of ebraphenol E.

Table 1. ${ }^{1} \mathrm{H}$ NMR $(600 \mathrm{MHz})$ and ${ }^{13} \mathrm{C}$ NMR $(150 \mathrm{MHz})$ data for $\mathbf{1}$ and $\mathbf{2}(\delta$ in ppm)

\begin{tabular}{|c|c|c|c|c|}
\hline \multirow{2}{*}{ No. } & \multicolumn{2}{|l|}{1} & \multicolumn{2}{|l|}{2} \\
\hline & $\delta_{\mathrm{H}}$, mult. $(J$ in $\mathrm{Hz})$ & $\delta_{\mathrm{C}}$ & $\delta_{\mathrm{H}}$, mult. $(J$ in $\mathrm{Hz})$ & $\delta_{\mathrm{C}}$ \\
\hline 1 & $7.03(1 \mathrm{H}, \mathrm{d}, 8.4)$ & 122.2 & $7.07(1 \mathrm{H}, \mathrm{d}, 8.4)$ & 123.0 \\
\hline 2 & $6.72(1 \mathrm{H}, \mathrm{d}, 8.4)$ & 114.6 & $6.74(1 \mathrm{H}, \mathrm{d}, 8.4)$ & 115.2 \\
\hline 3 & & 152.0 & & 151.7 \\
\hline 4 & & 124.3 & & 123.9 \\
\hline 5 & & 135.2 & & 134.5 \\
\hline 6 & $2.09(1 \mathrm{H}, \mathrm{m}) 1.75(1 \mathrm{H}, \mathrm{m})$ & 32.3 & $4.27(2 \mathrm{H}, \mathrm{dd}, 3.61 .2)$ & 28.8 \\
\hline 7 & $4.63(1 \mathrm{H}, \mathrm{m})$ & 74.8 & $\begin{array}{c}1.82(1 \mathrm{H}, \mathrm{dt}, 14.41 .2) \\
1.65(1 \mathrm{H}, \mathrm{m})\end{array}$ & 74.3 \\
\hline 8 & $1.74(1 \mathrm{H}, \mathrm{m})$ & 35.6 & $2.14(1 \mathrm{H}, \mathrm{m})$ & 31.1 \\
\hline 9 & & 37.1 & & 36.9 \\
\hline 10 & & 142.5 & & 141.2 \\
\hline 11 & $\begin{array}{l}2.34(1 \mathrm{H}, \mathrm{m}) \\
2.03(1 \mathrm{H}, \mathrm{m})\end{array}$ & 34.1 & $2.03(1 \mathrm{H}, \mathrm{dt}, 12.63 .0)$ & 33.8 \\
\hline 12 & $\begin{array}{l}1.65(1 \mathrm{H}, \mathrm{m}) \\
1.38(1 \mathrm{H}, \mathrm{m})\end{array}$ & 32.6 & $\begin{array}{l}1.69(1 \mathrm{H}, \mathrm{m}) \\
1.39(1 \mathrm{H}, \mathrm{m})\end{array}$ & 32.9 \\
\hline 13 & & 36.3 & & 36.6 \\
\hline 14 & $\begin{array}{l}1.44(1 \mathrm{H}, \mathrm{m}) \\
1.18(1 \mathrm{H}, \mathrm{m})\end{array}$ & 39.7 & $\begin{array}{c}1.51(1 \mathrm{H}, \mathrm{m}) \\
1.19(1 \mathrm{H}, \mathrm{dt}, 13.23 .0)\end{array}$ & 39.3 \\
\hline 15 & $5.86(1 \mathrm{H}, \mathrm{dd}, 17.4,10.8)$ & 150.9 & $5.88(1 \mathrm{H}, \mathrm{dd}, 17.4,10.2)$ & 151.2 \\
\hline 16 & $\begin{array}{l}4.97(1 \mathrm{H}, \mathrm{dd}, 17.4,1.2) \\
4.90(1 \mathrm{H}, \mathrm{dd}, 10.8,1.2)\end{array}$ & 109.0 & $\begin{array}{l}4.97(1 \mathrm{H}, \mathrm{dd}, 17.4,1.2) \\
4.89(1 \mathrm{H}, \mathrm{dd}, 10.2,1.2)\end{array}$ & 108.9 \\
\hline 17 & $0.99(3 \mathrm{H}, \mathrm{s})$ & 22.5 & $1.06(3 \mathrm{H}, \mathrm{s})$ & 23.0 \\
\hline 18 & $2.21(3 \mathrm{H}, \mathrm{s})$ & 11.9 & $2.21(3 \mathrm{H}, \mathrm{s})$ & 11.0 \\
\hline 19 & $1.12(3 \mathrm{H}, \mathrm{s})$ & 20.9 & $0.97(3 \mathrm{H}, \mathrm{s})$ & 20.9 \\
\hline $\mathrm{OCH}_{3}$ & $3.39(3 \mathrm{H}, \mathrm{s})$ & 54.9 & $3.45(3 \mathrm{H}, \mathrm{s})$ & 56.0 \\
\hline
\end{tabular}

In consideration the planar structure of compound $\mathbf{1}$, the relative configuration was determined on the basis of NOESY spectroscopic data. Based on the rosane type skeleton, the correlations between $\mathrm{H}-17$ and $\mathrm{H}-8$, and between methoxy protons and $\mathrm{H}-8$ indicated $\alpha$ orientations for $17-\mathrm{CH}_{3}$ and 7- $\mathrm{OCH}_{3}$ (Figure 2). The ECD spectrum of $\mathbf{1}$ has been measured, together with the calculated ECD spectra for stereoisomers (Figure 3 ). As a result, the absolute configuration of $\mathbf{1}$ was determined to be $7 R, 8 R, 9 R, 13 R$. Therefore, compound $\mathbf{1}$ was identified to be an aromatic rosane type diterpenoid possessing methoxy group, named ebraphenol $\mathrm{E}$.

Lipase in digestive tract plays a key role in the absorption of dietary fat. It can hydrolyze triglycerides to glycerides, glycermonoesters and free fatty acids, which plays key role for fat development. Thus, the inhibitor of lipase could be used to treat obesity. In the present work, 
ebraphenol E (1) could inhibit the hydrolase function of lipase with $\mathrm{IC}_{50}$ value $12.5 \mu \mathrm{M}$, which was suggested to be lipase inhibitory agent.

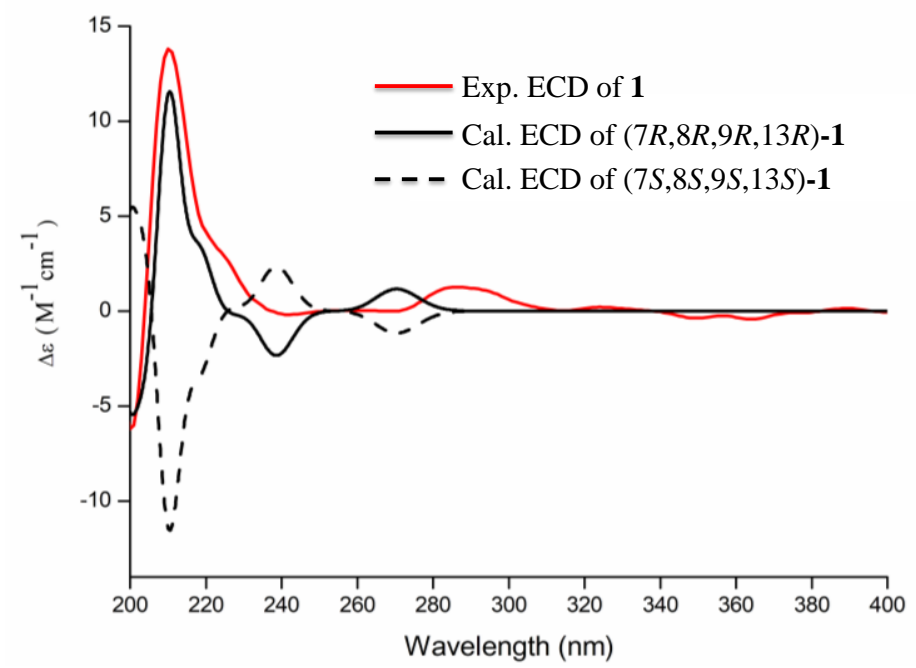

Figure 3. The experimental ECD and calculated ECD spectra of compound 1

\section{Chemotaxonomic significance}

Previous phytochemical investigations of E. ebracteolata have revealed the existences of diterpenoids as the major bioactive constituents. As shown in Figure S2 (Supporting information), the isolated diterpenoids were determined to be tricyclic diterpenoids, which displayed structural diversity, including rosanes (1-18), abietanes (19-31), and atisanes (32-37) [16-18, 20]. The abietanes possessing $\alpha, \beta$-unsaturated lactone ring together with atisanes have been isolated from euphorbiaceae as the major constituents previously. On the other hand, for the phytochemical investigations about plant materials, rosane type diterpenoid is an important structural classification, which is widely distributed. However, rosane type diterpenoids possessing an aromatic ring A are not explored for other plants, except for E. ebracteolata. The aromatic ring A of rosane indicated the high expression of dehydrogenase in E. ebracteolata. These rosanes together with dehydrogenase suggested the distinction between E. ebracteolata and the other species of euphorbiaceae. Therefore, various diterpenoids were revealed as the major chemical constituents of E. ebracteolata, especial rosanes and abietanes. Additionally, rosanes possessing aromatic ring A could be determined to be chemotaxonomic makers of E. ebracteolata.

\section{Acknowledgments}

This work was partially supported by National Natural Science Foundation of China (Nos. 81872970, 81930112, 81960703, 81560632 and 81660620).

\section{Supporting Information}

Supporting Information accompanies this paper on http://www.acgpubs.org/journal/recordsof-natural-products

\section{ORCID}

Jian Zhou: 0000-0002-3544-6032

Jinhua Wen: 0000-0003-3979-340X

Jianhua Huang: 0000-0001-8506-8255

Pengfei Chen: 0000-0002-1363-7911

Xiaochi Ma: 0000-0003-4397-537X

Rongjing Sun: 0000-0002-6694-4501

Chao Wang: 0000-0002-6251-7908 


\section{References}

[1] Chinese Pharmacopoeia Commission (2015). Chinese Pharmacopoeia, China Medical Science Press, Beijing, pp.286.

[2] B. Deng, S. Z. Mu, J. X. Zhang and X. J. Hao (2010). New diterpenoids from the roots of Euphorbia ebracteolata Hayata, Nat. Prod. Res. 24, 1503-1509.

[3] X. Y. Wang, L. P. Liu, T. G. Kang and H. B. Wang (2012), Chemical constituents of Euphorbia ebracteolata, Chin. J. Nat. Med. 10, 299-302.

[4] Z. Q. Yin, C. L. Fan, W. C. Ye, R. W. Jiang, C. T. Che, T. C. W. Mak, S. X. Zhao and X. S. Yao (2005). Acetophenone derivatives and sesquiterpene from Euphorbia ebracteolata, Planta Med. 71, 979-982.

[5] X. Liu, W. C. Ye, B. Yu, S. X. Zhao, H. M. Wu and C. T. Che (2004). Two new flavonol glycosides from Gymnema sylvestre and Euphorbia ebracteolata, Carbohydr. Res. 339, 891-895.

[6] G. M. Fu, B. Y. Yu and D. N. Zhu (2006). Two novel phloroglucinol derivatives from Euphorbia ebracteolata hayata, J. Asian Nat. Prod. Res. 8, 149-153.

[7] X. Sun, and S. Wang (1999). Studies on chemical constituents of Euphorbia ebracteolata Ilayata, Zhongguo Zhong Yao Za Zhi 24, 226-227.

[8] G. M. Fu, H. L. Qin, S. S. Yu and B. Y. Yu (2006). Yuexiandajisu D, a novel 18-nor-rosane-type dimeric diterpenoid from Euphorbia ebracteolata Hayata, J. Asian Nat. Prod. Res. 8, 29-34.

[9] N. Zhang, H. Cai, B. C. Cai, H. J. Yang, J. S. Li and G. M. Yang (2010). Two new cytotoxic acetophenone derivatives from Euphorbia ebracteolata Hayata. Fitoterapia 81, 385-388.

[10] Z. G. Liu, Z. L. Li, J. Bai, D. L. Meng, N. Li, Y. H. Pei, F. Zhao and H. M. Hua (2014). Antiinflammatory diterpenoids from the roots of Euphorbia ebracteolata, J. Nat. Prod. 77, 792-799.

[11] Y. S. Huang, Y. Lu, C. H. Chen , K. H. Lee and D. F. Chen (2019). Potent anti-HIV ingenane diterpenoids from Euphorbia ebracteolata, J. Nat. Prod. 82, 1587-1592.

[12] Z. L. Yu, Y. L. Wei, X. G. Tian, Q. L. Yan, Q. S. Yan, X. K. Huo, C. Wang, C. P. Sun, B. J. Zhang and X. C. Ma (2018). Diterpenoids from the roots of Euphorbia ebracteolata and their anti-tuberculosis effects, Bioorg. Chem. 77, 471-477.

[13] A. H. Wang, X. K. Huo, L. Feng, C. P. Sun, S. Deng, H. L. Zhang, B. J. Zhang, X. C. Ma, J. M. Jia and C. Wang (2017). Phenolic glycosides and monoterpenoids from the roots of Euphorbia ebracteolata and their bioactivities, Fitoterapia 121, 175-182.

[14] A. Wang, X. Gao, X. Huo, S. Huang, L. Feng, C. Sun, B. Zhang, X. Ma, J. Jia and C. Wang (2017). Antioxidant acetophenone glycosides from the roots of Euphorbia ebracteolata Hayata, Nat. Prod. Res. 32, 2189-2192.

[15] A. H. Wang, X. G. Tian, Y. L. Cui, X. K. Huo, B. J. Zhang, S. Deng, L. Feng, X. C. Ma, J. M. Jia and C. Wang (2018). Diterpenoids from the roots of Euphorbia ebracteolata and their inhibitory effects on human carboxylesterase 2. Phytochemistry 146, 82-90.

[16] B. Wang, Y. L. Wei, X. Y. Zhao, X. G. Tian, J. Ning, B. J. Zhang, S. Deng, D. W. Li, X. C. Ma and C. Wang (2018). Unusual ent-atisane type diterpenoids with 2-oxopropyl skeleton from the roots of Euphorbia ebracteolata and their antiviral activity against human rhinovirus 3 and enterovirus 71, Bioorg. Chem. 81, 234-240.

[17] C. Wang, Q. S. Yan, Y. F. Wang, S. S. Huang, J. Ning, L. Feng, C. P. Sun, B. J. Zhang, D. W. Li and X. C. Ma (2019). Ebracpenes A and B, unusual ring C-seco and ring D-aromatic nortriterpenoids, from Euphorbia ebracteolata and lipase inhibitory evaluation, J. Org. Chem. 84, 1624-1629.

[18] C. H. Han, Y. L. Peng, Y. F. Wang, X. K. Huo, B. J. Zhang, D. W. Li, A. J. Leng, H. L. Zhang, X. C. Ma and C. Wang (2018). Cytotoxic ent-Abietane-type diterpenoids from the roots of Euphorbia ebracteolata, Bioorg. Chem. 81, 93-97.

[19] Y. L. Wei, C. Wang, Z. B. Cheng, X. G. Tian, J. M. Jia, Y. L. Cui, L. Feng, C. P. Sun, B. J. Zhang and X. C. Ma (2017). Heterodimeric diterpenoids isolated from Euphorbia ebracteolata roots and their inhibitory effects on $\alpha$-glucosidase, J. Nat. Prod. 80, 3218-3223.

[20] L. Li, D. W. Li, C. R. Wang, L. Feng, Z. L. Yu, J. Ning, B. J. Zhang, H. L. Zhang, C. Wang and X. C. $\mathrm{Ma}$ (2020). Aromatic rosane diterpenoids from the roots of Euphorbia ebracteolata and their inhibitory effects against lipase, Bioorg. Chem. 94, 103360.

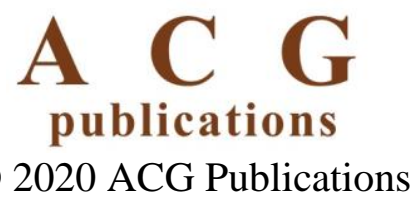

